\title{
Primeros Atlas Anatómicos Utilizados en la Formación de Médicos en Chile
}

\author{
First Anatomical Atlas Used in the Training of Physicians in Chile
}

\author{
Juan Silva ${ }^{1,2,3}$; Claudia Araya ${ }^{1}$; Julio Cárdenas ${ }^{2}$; Bárbara Mansilla ${ }^{1}$; Alexis Latín ${ }^{1}$ \& Matías Salazar ${ }^{1}$
}

SILVA, J.; ARAYA, C.; CÁRDENAS, J.; MANSILLA, B.; LATÍN, A. \& SALAZAR, M. Primeros atlas anatómicos utilizados en la formación de médicos en Chile. Int. J. Morphol., 38(5):1302-1310, 2020.

RESUMEN: En Chile, los primeros médicos se formaron en la Universidad Real de San Felipe y el Instituto Nacional, entre 1758 y 1833. Sus maestros Domingo Nevín, Manuel Chaparro y Pedro Morán, usaron y recomendaron los pocos libros existentes. El objetivo de este trabajo fue analizar estos libros con ilustraciones anatómicas que se utilizaron durante este período y en las que los primeros estudiantes de medicina encontraron una guía visual para la comprensión de la anatomía humana y la práctica de la disección. Para este estudio, se analizaron los trabajos de Lorenz Heister (1755), Martin Martínez (1764), Friedrich Tiedemann (1822a,b) y François Chaussier (1823). Para estos autores, se desarrolló una síntesis con datos biográficos relevantes. Para los libros se realizó un análisis bibliográfico, cuantitativo y descriptivo-cualitativo. Las imágenes también se analizaron según las clasificaciones de Gómez (2005), Choulant (1852) y Kemp (1990). En cuanto a los autores de los textos, eran médicos, cirujanos, anatomistas y / o legistas médicos, de origen alemán, español o francés. Los textos están escritos en español, francés, alemán y/o latín. Presentan imágenes con diferentes niveles de detalle, en blanco y negro o en color. Toda la bibliografía anatómica utilizada durante el período de estudio es de origen europeo, transfiriéndose a través de sus páginas, una realidad centrada en la Europa de los siglos XVIII y XIX. Esta visión sesgada del conocimiento se ha mantenido hasta ahora, donde la enseñanza de la anatomía humana todavía se basa en textos de origen extranjero. El estudio profundo de las características de la formación de médicos en Chile es esencial para comprender el nacimiento de la identidad profesional, que ha sido de gran influencia en las ciencias de la salud y en la historia político-social de Chile.

PALABRAS CLAVE: Historia de Chile; Historia de la medicina; Historia de la anatomía; Bibliografía anatómica; Atlas anatómicos.

\section{INTRODUCCIÓN}

En Chile durante los siglos XVII y XVIII existía la imperiosa necesidad de contar con un centro de formación profesional. Hasta 1738, los habitantes de esta colonia debían enviar a sus hijos al Virreinato del Perú para hacer sus estudios superiores médicos, ya que la enseñanza superior estaba restringida a la carrera eclesiástica dictada en la Pontificia Universidad de Santo Tomás (1619 - 1747) de los Padres Dominicos (Orden religiosa de Predicadores u Orden Dominicana) o en la Universidad Pontificia Colegio Máximo de San Miguel (1625 - 1767) de los Hermanos Jesuitas (Orden religiosa de la Compañía de Jesús). Para remediar esta desfavorable situación, los vecinos de Santiago solicitaron a España empeñosamente la creación de una universidad real que impartiera cátedras de leyes y medicina (Departamento de Estadística del Servicio de
Bienestar Estudiantil de la Universidad de Chile, 1941; Barros Arana, 2001).

Con la fundación de la Universidad Real de San Felipe (USF) en la ciudad de Santiago, se estableció la primera Cátedra de Prima Medicina en 1758, pero su nivel académico fue inferior al de otras universidades americanas y funcionó en forma intermitente matriculando solo a 38 alumnos entre 1758 y 1839 (Serrano, 2016).

En este curso se nombró profesor al Dr. Domingo Nevín McHugh (irlandés 1722 - 1770, médico). Desde el punto de vista curricular, la carrera comprendía 4 años lectivos y 2 años de práctica en el Hospital San Juan de Dios (HSJD) y su horario de clases consideraba una hora de lec-

\footnotetext{
${ }^{1}$ Facultad de Medicina y Ciencia, Universidad San Sebastián, Santiago. Chile.

${ }^{2}$ Departamento de Anatomía y Medicina Legal, Facultad de Medicina, Universidad de Chile, Santiago. Chile.

${ }^{3}$ Programa de Doctorado en Educación, Universidad Bernardo O’Higgins, Santiago. Chile.
} 
tura diaria de las obras de Hipócrates, Galeno y Avicena y a continuación, media hora de discusión (Grossi, 1895; Medina, 1928; Laval, 1958).

El curso se dictaba en latín y la enseñanza era principalmente memorística, con estricto ajuste a textos o dictados. En este plan de estudios no existía formalmente la enseñanza práctica de la anatomía, aun así y en forma complementaria, el Dr. Nevín dedicaba 4 horas todas las tardes a los alumnos en el HSJD, donde enseñó la anatomía, los rudimentos de la fisiología, los cuadros patológicos y la enseñanza práctica de la clínica (Hernández, 1934; Mellafe et al., 1992; Cruz-Coke, 1995; Barros Arana; Laval \& Duarte, 2016). No existen antecedentes de que esta enseñanza fuera apoyada con imágenes impresas de algún tipo (Cárdenas-Valenzuela, 2019).

Posterior a la muerte del Dr. Nevín en 1770, y en forma paralela a la educación formal en las aulas de la USF, el Dr. Pedro Manuel Chaparro (chileno 1745 - 1811, médico), se dedicó en forma extraoficial a la formación de médicos y cirujanos. Para el Dr. Chaparro, la enseñanza de la anatomía era tan fundamental que exigía a los estudiantes su estudio durante 5 años y aconsejaba que en los 2 primeros se enseñase con el Compendio Anatómico de Lorenzo Heister (alemán 1683 - 1758, médico y anatomista) y con la Anatomía Completa del Hombre de Martín Martínez (español, 1684 - 1734, médico y anatomista) (Medina; Laval, 1964; Cruz-Coke; Laval \& Duarte).

Más tarde, durante el primer tercio del siglo XIX, comenzó la apertura del continente iberoamericano a las influencias europeas, los nuevos países liberados del régimen colonial formaron escuelas de medicina republicanas influidas por el espíritu de médicos europeos. Como resultado de este proceso, la medicina hispanoamericana sufrió una completa transformación en sus objetivos, su espíritu y su dinámica social (Cruz Coke). Este influjo cultural desde el continente aumentó los recursos disponibles (humanos, técnicos, científicos y bibliográficos, entre otros).

Durante este último periodo, una de las preocupaciones principales para las autoridades chilenas, posterior al turbulento periodo de la Independencia y Reconquista (1810 a 1818), fue la de fundar un establecimiento educacional que sirviera como modelo para la educación pública chilena, así "todos los niveles educativos, todos los campos del saber, su cultivo y su aplicación, estarían comprendidos en él", incluyendo los estudios superiores de teología, ciencias naturales, derecho y medicina. Este establecimiento se fundó en 1813, durante el gobierno del General José Miguel Carrera (chileno 1785 - 1821, militar) y se denominó "Instituto Nacional, Literario, Económico, Civil y Eclesiástico del Estado" (IN) (Serrano).
La formación de médicos en el IN inició en 1833 y el profesorado de esta Escuela Médica (EM33) fueron el Dr. William Cunningham Blest Maiben (irlandés 1800 - 1884, médico), el Dr. Pedro Morán (chileno 1771 - 1840, médico y cirujano) y Don José Vicente Bustillos (chileno 1800 1873, farmacéutico). De estos, el Dr. Morán fue nombrado Profesor de Anatomía (Sotomayor, 1869; Grossi; CruzCoke).

Cuando se inauguró el Anfiteatro Anatómico en el HSJD (septiembre 9 de 1833), el Dr. Morán en su discurso señaló “...para (el curso) anatómico, puesto bajo mis débiles luces, tomé por tipo a los señores François Chaussier (francés 1746 - 1828, médico y anatomista), Xavier Bichat (francés 1771-1802, médico y anatomista) y Jaques-Pierre Maygrier (francés 1771 - 1835, médico y anatomista)..." (Ferrer, 1904; Orrego Luco, 1922; Laval, 1958; Silva et al., 2019).

Al parecer, los recursos con que contó la EM33, debieron ser bastante precarios, pues en nota enviada al Gobierno el 1 de octubre de 1834, el Dr. Morán solicitaba encarecidamente, se le facilitara un atlas anatómico de arterias de Friedrich Tiedemann (alemán 1781 - 1861, médico y anatomista), que existía en la Biblioteca Nacional (Laval, 1964).

El análisis histórico del periodo permitió identificar los textos que presentan imágenes anatómicas y que probablemente apoyaron la práctica de la disección cadavérica durante los primeros años de vida de la EM33. Estas primeras fuentes corresponden a 2 libros de texto con imágenes intercaladas (Heister, 1755; Martínez, 1764) y 2 atlas anatómicos propiamente tales (Tiedemann, 1822a,b; Chaussier, 1823).

El objetivo de este trabajo fue analizar los libros utilizados en el periodo que comprende a la USF y al IN desde 1758 a 1833 , en los cuales los primeros estudiantes de medicina encontraron una guía visual para el entendimiento de la anatomía humana y la práctica de la disección, pilares fundamentales para el ejercicio clínico de la medicina y la cirugía de aquella época.

\section{MATERIAL Y MÉTODO}

Se utilizaron diversos y múltiples repositorios académicos, realizando una búsqueda dirigida de los textos y atlas mencionados en el análisis histórico entre los años 1758 a 1833. Una vez hallados (en formato digital) se imprimieron y encuadernaron. 
Para la reseña biográfica de los autores, se investigó y registró en tabla ad hoc, los datos más relevantes de cada uno de ellos (nombre, año de nacimiento y muerte, nacionalidad, ciudad donde nacieron, profesión y producción literaria).

Las características bibliográficas de los textos comprendió el autor, el título del libro, el lugar de publicación, el idioma en que fue escrito, el año de publicación y las observaciones pertinentes a este análisis.

El análisis cuantitativo del texto comprendió, la existencia de introducción y/o prefacio, cantidad de páginas totales, cantidad de páginas con imágenes, porcentaje de páginas con imágenes en relación con el total de páginas del recurso, presencia de leyendas, descripción y/o rotulación de las imágenes, si las imágenes son en color o no, si la obra incluye un índice de imágenes y observaciones pertinentes al análisis.

La clasificación de las imágenes fue realizada con los métodos incluidos y descritos en el trabajo de Dinator (2014). Estas clasificaciones son las siguientes:

\section{Clasificación propuesta por Gómez, S. (2005):}

a) Ornamental (Orn): imágenes que solo tienen un valor estético y retórico, son independientes del texto que acompañan, siendo recursos prescindibles.

b) Pedagógicas (Ped): imágenes que acompañan textos masivos de divulgación científica destinados a un público no especializado.

c) Descriptivas (Des): imágenes que transmiten experiencias directas de objetos y fenómenos como mapas, herbarios, ilustraciones anatómicas y zoológicas, entre otras.

d) Explicativas (Exp): imágenes que buscan facilitar la comprensión de razonamientos que explican un fenómeno, en términos visuales.

e) Información gráfica de datos (IGD): imágenes que mediante convenciones y símbolos buscan entregar datos obtenidos empíricamente.

\section{Clasificación propuesta por Choulant, L. (1852):}

a) Representación de la parte (RdP): imágenes que son construidas en base a un solo individuo en particular. Son características de la anatomía patológica, pero han sido ampliamente usadas también en anatomía normal.

b) Tipificación (Tip): imágenes basadas en múltiples observaciones y que tienen su origen en el razonamiento de los anatomistas-científicos, quienes construyen el recurso en relación a como debiera verse y entenderse la realidad.

c) Esquematización (Esq): imágenes construidas simplificando los elementos propios de la estructura, centrándose en definir determinadas formas para comunicar aspectos concretos del objeto de estudio.

\section{Clasificación propuesta por Kemp, M. (1990):}

a) Estilo heroico en el humanismo anatómico (HHA): imágenes muy estilizadas donde las figuras centrales posan como los protagonistas de un drama heroico en escenarios y paisajes reminiscentes al periodo clásico, las estructuras se presentan en funcionamiento a través de formas que insinúan movimientos. Son características de las épocas prevesalianas y evaden la realidad cadavérica y los procedimientos propios de la disección.

b) Retórica de lo real (RdR): imágenes donde el énfasis este puesto en reflejar la realidad del cuerpo humano de manera objetiva. El aspecto más importante de este estilo consiste en convencer a otros de la veracidad de las imágenes.

c) Estilo "no-estilo" (EnE): imágenes donde se elimina la expresión artística, en función del objetivo científico, dejando de lado todos los recursos retóricos, para configurar líneas planas y simples. Se conjuga el naturalismo gráfico y esquemático en virtud de generar esquemas simples y claros. Son imágenes centradas en lo pedagógico.

Finalmente se realizó un análisis descriptivo - cualitativo de los textos, en el que se consideró las características de diseño y de calidad de las imágenes de cada obra.

\section{RESULTADOS Y DISCUSIÓN}

Todos los libros nombrados en el análisis histórico fueron encontrados. Sus referencias bibliográficas son las siguientes:

1. Heister, L. Compendio anatómico que brevissimamente comprehende, y explica esta ciencia. Madrid, Imp. de los Herederos de Don Miguel Francisco Rodriguez, 1755 (Fig. 1a).

2. Martínez, M. Anatomía completa del hombre con todos sus hallazgos, nuevas doctrinas y observaciones raras hasta el tiempo presente y muchas advertencias necessarias para la cirugía según el método que se explica en nuestro theatro de Madrid. Madrid, Imp. de la Viuda de Manuel Fernández, 1764 (Fig. 2a).

3.Tiedemann, F. Tabulae arteriarum corporis humani. Carlsruhae, Ed. ex Officina Christiani Friderici Müller, Typographi, Litographi et Bibliopolae Aul, 1822 y Tiedemann, F. Erklärungen seiner abbildungen der pulsadern des menschlichen kórpers. Carlsruhae, Ed. Verlag der C. F. Müller'schen Hofbuchhandlung, 1822 (Fig. 3a).

4. Chaussier, M. Planches Anatomiques a lúsages des jeunes gens qui se destinenta létude de la chirurgie, de la médecine, de la peinture et de la sculpture. Paris, Ed. Chez C. L. F Panckoucke, 1823 (Fig. 4a). 

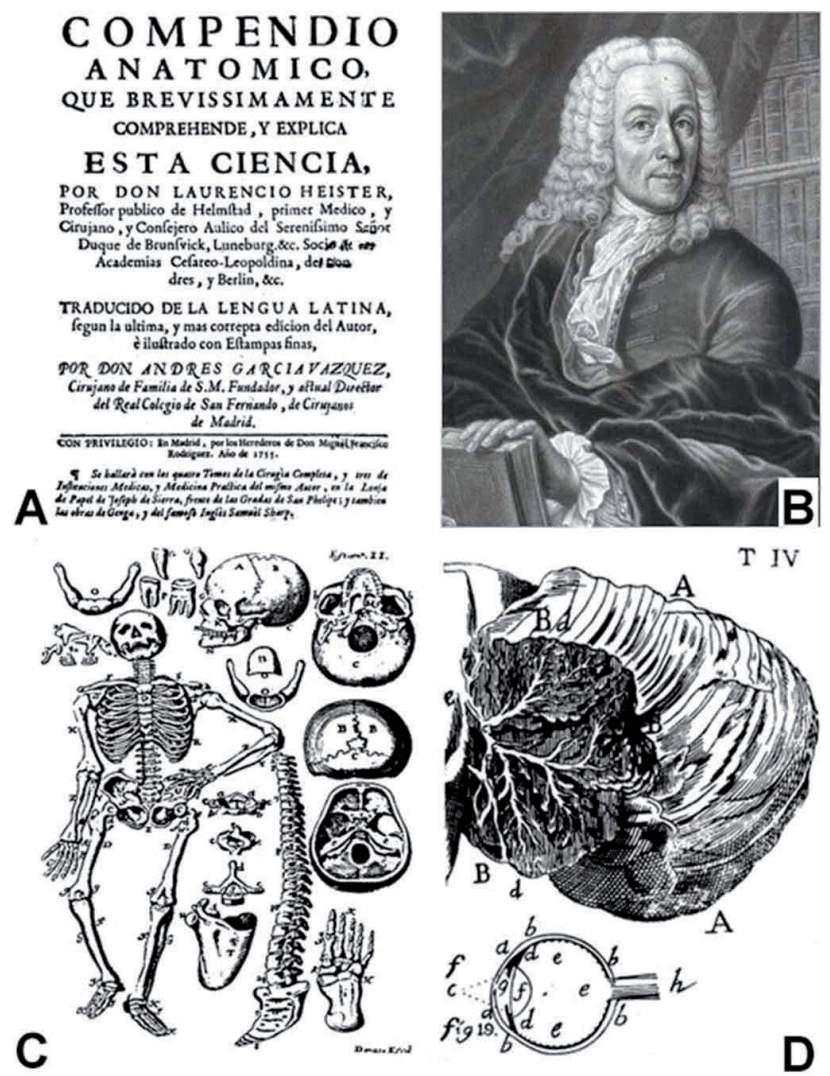

Fig. 1. Ejemplos de imágenes del libro de Heister, 1755. En A).frontispicio del libro; en B).- retrato de Lorenz Heister; en C).- imagen identificada como "tabla segunda de osteología"; en D).- imagen perteneciente a la "tabla IV" del texto.
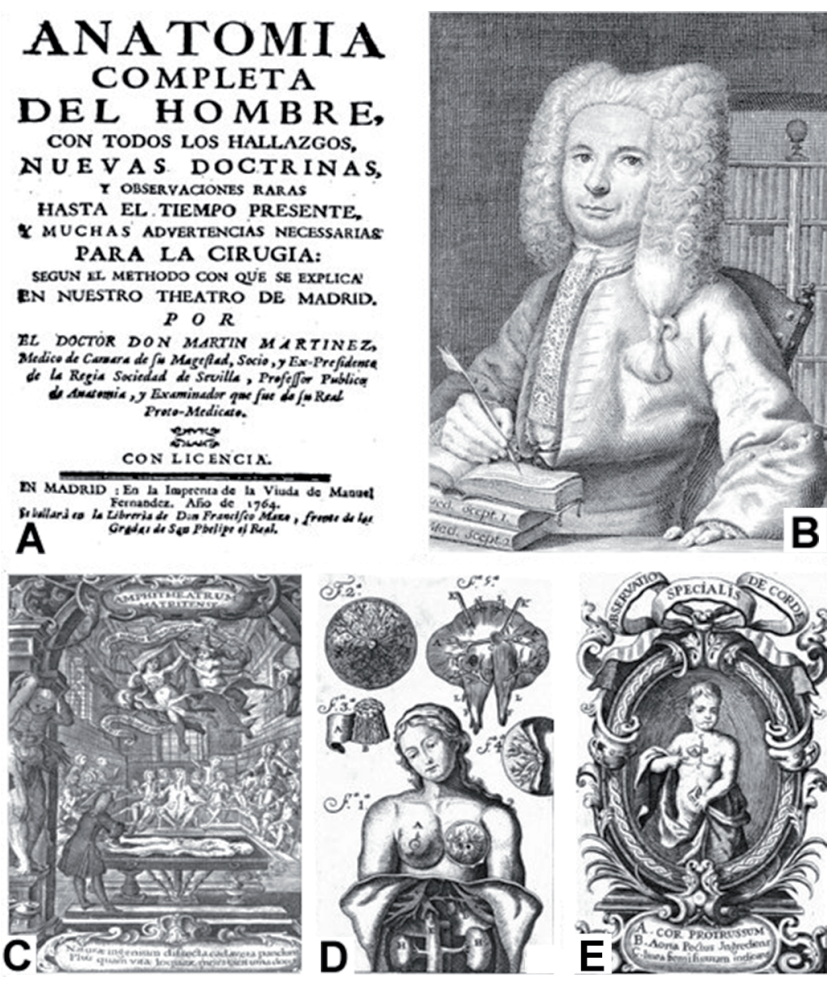

Fig. 2. Ejemplos de imágenes del libro de Martínez, 1764. En A. frontispicio del libro; en B. retrato de Martín Martínez; en C. primera imagen de la obra la cual corresponde a una Lección de Anatomía realizada en el Anfiteatro del Hospital General de Madrid. Esta imagen corresponde un grabado de Matías de Irala (1728); en D. imagen identificada como "estampa VIII donde se muestran los pechos de la muger, y el diaphragma"; en E. imagen identificada como "estampa $\mathrm{X}$, cor protrussum", dentro del capítulo "casos raros".

Tabla I. resumen de los datos biográficos de los autores de los textos que contenían ilustraciones anatómicas y que fueron utilizados por los estudiantes de medicina de Chile, desde 1758 y hasta 1840 (N-M, años de nacimiento y muerte del autor).

\begin{tabular}{|c|c|c|c|c|c|}
\hline Autor & $\mathrm{N}-\mathrm{M}$ & Nacionalidad & $\begin{array}{c}\text { Lugar de } \\
\text { nacimiento }\end{array}$ & Profesión & Otras obras \\
\hline $\begin{array}{l}\text { Lorenz } \\
\text { Heister }\end{array}$ & $1683-1758$ & Alemán & $\begin{array}{l}\text { Frankfurt, } \\
\text { Alemania }\end{array}$ & $\begin{array}{l}\text { Médico, Cirujano y } \\
\text { Anatomista }\end{array}$ & $\begin{array}{l}\text { 1.Chirurgie (1739). } \\
\text { 2. Instituciones Chirurgicae (1749). }\end{array}$ \\
\hline $\begin{array}{l}\text { Martin } \\
\text { Martínez }\end{array}$ & $1684-1734$ & Español & $\begin{array}{l}\text { Madrid, } \\
\text { España }\end{array}$ & Médico y Anatomista & $\begin{array}{l}\text { 1. Medicina escéptica y cirugía moderna (1722-1725). } \\
\text { 2. Noches anatómicas, o anatomía compendiosa (1716). } \\
\text { 3. Examen nuevo de cirugía modema (1725). }\end{array}$ \\
\hline $\begin{array}{l}\text { Friedrich } \\
\text { Tiedemann }\end{array}$ & $1781-1861$ & Alemán & $\begin{array}{l}\text { Kasell, } \\
\text { Alemania }\end{array}$ & Médico y Anatomista & $\begin{array}{l}\text { 1. Anatomie der Bildungsgeschichte des Gehirns (1816). } \\
\text { 2. On the Brain of the Negro, compared with that of the } \\
\text { European and the Orang-Outang (1836). } \\
\text { 1. Manuel médico-legal des poisons (1824). }\end{array}$ \\
\hline $\begin{array}{l}\text { François } \\
\text { Chaussier }\end{array}$ & $1746-1828$ & Francés & $\begin{array}{l}\text { Dijon, } \\
\text { Francia }\end{array}$ & $\begin{array}{l}\text { Médico, Médico - } \\
\text { legista y Anatomista }\end{array}$ & $\begin{array}{l}\text { 2. Recueil de mémoires, consultations, et rapports sur } \\
\text { divers objets de médecine légale (1824). } \\
\text { 3. Mémoire médico-legal sur la viabilité de l'enfant } \\
\text { naissant (1826) }\end{array}$ \\
\hline
\end{tabular}

Los resultados de la reseña biográfica de los autores pueden observarse en la Tabla I. Es posible destacar que los textos fueron desarrollados por autores españoles, alema- nes y franceses, y que estos eran médicos, anatomistas, cirujanos y/o médico-legistas. Retratos de estos autores se observan en las Figuras 1b, 2b, 3b y 4b. 

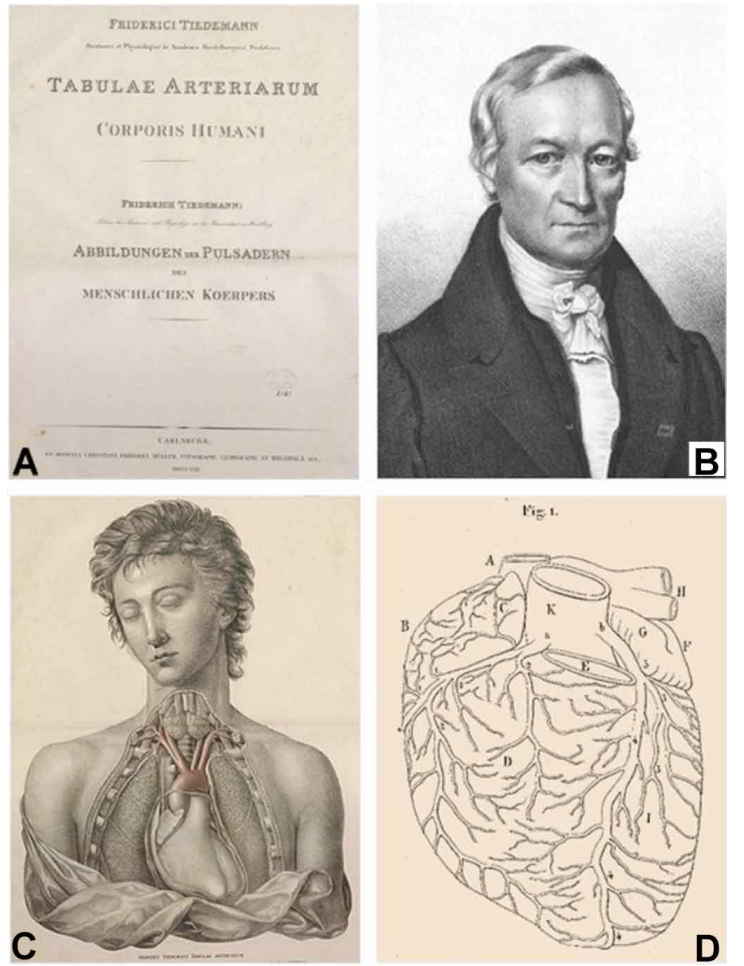

Fig. 3. Ejemplos de imágenes del libro de Tiedemann, 1822. En A. frontispicio del libro; en B. retrato de Friedrich Tiedemann; en C. imagen correspondiente a la "tabla prima: exhibet haec tabula situm cordis et aortae in cadavere viri viginti quatuor annorum"; en D. imagen correspondiente a la "imagen 1 de la tabla II: sistit arterias coronarias cordis seu cardiacas a facie anteirori”.
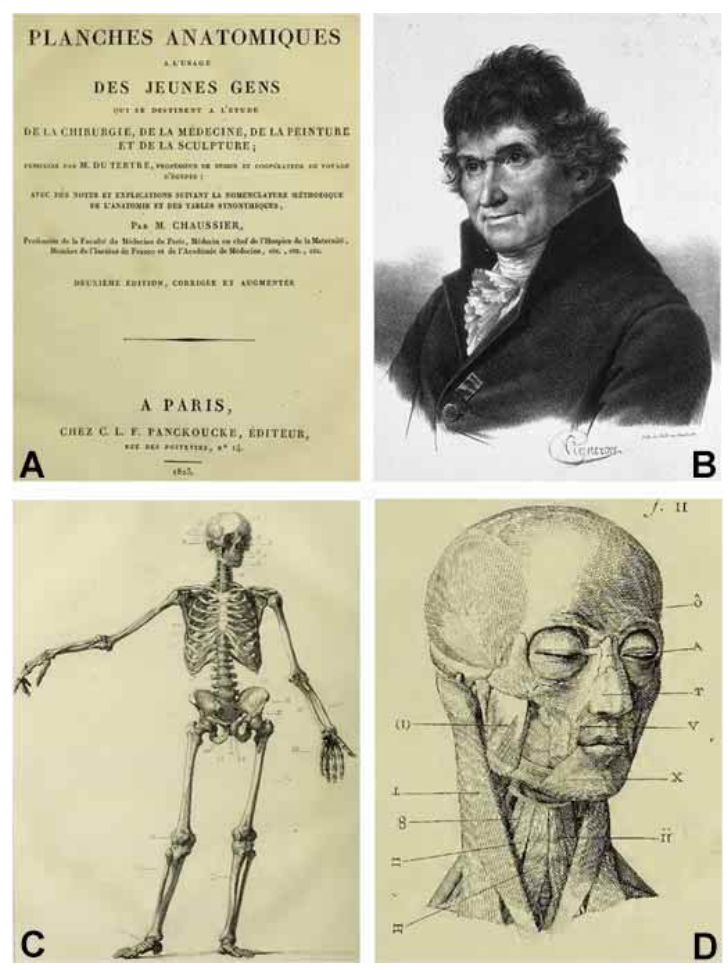

Las características bibliográficas de los textos se pueden observar en la Tabla II. Es posible destacar que fueron escritos en español, francés, alemán y latín. También es posible observar que los libros recomendados por el Dr. Chaparro, presentan recursos visuales (Heister; Martínez), pero será una vez iniciada la formación médica en el IN cuando aparecen los atlas propiamente tales (Tiedemann, 1822a,b; Chaussier), ambos utilizados por el Dr. Morán. Por último, la mitad de las obras son libros de texto con imágenes intercaladas, mientras que la otra mitad son atlas anatómicos propiamente tales.

Los resultados del análisis cuantitativo de los textos mencionados están representados en la Tabla III. Es destacable que la totalidad de los libros presentan leyendas y rótulos de sus imágenes y solo una obra presenta separados en dos tomos distintos, las imágenes y las explicaciones de estas.

Los resultados de la clasificación de las imágenes incluidas en los libros de texto y atlas se registran en la Tabla IV. Así, según la clasificación de Gómez, S. (2005), se evidenció imágenes tipo Des (Figs. 1c y d; 2d; 3c y d; 4c y d) y tipo Orn (Fig. 2c). Según la clasificación de Choulant, L. (1852), se evidenció la presencia de imágenes tipo RdP (Figs. 2e y 4c), tipo Tip (Figs. 1d, 2d, 3d y 4d) y tipo Esq (Figs. 1d y 2d) y por último según la clasificación de Kemp, M. (1990), se evidenció la presencia de imágenes tipo HHA (Figs. 2e y 4c), tipo RdR (Figs. 2d y 3c) y tipo EnE (Figs. 1c y d, 3c y 4d).

Los resultados del análisis descriptivo - cualitativo de las obras que fueron utilizadas en la formación teórica y práctica, de los primeros médicos en Chile, señalan:

1. Heister, 1755; en este texto, existen dos grupos de imágenes, todas en blanco y negro. Un primer grupo compuesto por 2 estampas con dibujos simples y con bajo nivel de detalles (las imágenes corresponden a una imagen del esqueleto de un infante de corta edad y otra del esqueleto de un adulto). El nivel de detalle representado solo permite el reconocimiento de algunas estructuras o en algunos casos, solo el hueso representado (Fig. 1c). Un segundo grupo de estampas, corresponden a conjuntos de imágenes agrupadas por temas. En estas, están representadas 41 estructuras en total que ilustran sobre diversos órganos (huesos del oído, huesos sesamoideos, estómago, intestino craso, apéndice vermiforme, vías hepáticas, tubas uterinas, hígado de neonato, músculo diafragma, glándula timo, cerebelo, ojo, lengua, paladar duro y blando, mandíbula, pene, testículo, vesícula seminal, embrión de cuatro semanas de ges-

Fig. 4. Ejemplos de imágenes del libro de Chaussier, 1823. En A. frontispicio del libro; en B. retrato de François M. Chaussier; en c).- imagen correspondiente a la "Planche I del Livre premier, précis de squelettologie"; en D. Imagen correspondiente a la "Fig. II de la Planche X del Livre second, précis de myologie". 
tación, ano y recto, senos de la duramadre, vómer y algunos músculos de la mano). Este último grupo de imágenes tienden a ser de mayor nivel de detalles que las primeras 2 (Fig. 1d). Todas las imágenes cuentan con sus respectivas explicaciones.

2. Martínez, 1764; en este texto, es posible evidenciar 25 páginas con imágenes. La primera imagen de la obra (Fig. 2c), corresponde a una Lección de Anatomía en el Anfiteatro del Hospital General de Madrid (grabado de Matías de Irala, 1728) y la segunda imagen (Fig. 2b) es el retrato del autor del libro (aguafuerte según dibujo de Valero Iriarte, siglo XVII). Todo el resto de las imágenes corresponde a estampas donde pueden observarse una o más ilustraciones anatómicas, todas en blanco y negro, relativamente simples, presentando un nivel de detalles suficiente para comprender la localización de órganos y características más importantes (Figs. 2d y 2e). En las últimas páginas del texto, es posible encontrar un índice de las imágenes contenidas en el plan de la obra.

3. Tiedemann, 1822; el atlas anatómico de este autor viene dividido en 2 tomos. El primer tomo corresponde a la colección de dibujos del atlas y contiene 75 páginas con imágenes, centradas principalmente en las arterias del cuerpo y contextualizadas en la región topográfica correspondiente (Fig. 3c). La gran mayoría de las imágenes contienen las estructuras óseas, articulares y musculares. Cuando es de importancia, aparecen incluidos órganos y en algunas es posible observar grandes venas. Es importante destacar que cada imagen viene representada 2 veces; una primera imagen, con exquisito nivel de detalles y en color (en color rojo, el contenido arterial y las estructuras colindantes en blanco y negro). La segunda imagen es un boceto de la primera imagen

Tabla II. Resumen de las características bibliográficas de los textos que contenían ilustraciones anatómicas y que fueron utilizados por los estudiantes de medicina de Chile, desde 1758 y hasta 1840.

\begin{tabular}{|c|c|c|c|c|c|c|}
\hline Autor & Título & Lugar & Idioma & Año & Tipo & Observaciones \\
\hline $\begin{array}{l}\text { Heister, } \\
\text { Lorenz }\end{array}$ & $\begin{array}{l}\text { Compendio anatómico que } \\
\text { brevissimamente compre hende, y } \\
\text { explica esta ciencia }\end{array}$ & $\begin{array}{l}\text { Madrid, } \\
\text { España }\end{array}$ & Español & 1755 & $\begin{array}{l}\text { Texto con } \\
\text { imágenes } \\
\text { intercaladas }\end{array}$ & $\begin{array}{l}\text { Traducción del original en } \\
\text { alemán, impreso en } 1721 \text { en } \\
\text { Alemania }\end{array}$ \\
\hline $\begin{array}{l}\text { Martínez, } \\
\text { Martin }\end{array}$ & $\begin{array}{l}\text { Anatomía completa del hombre, con } \\
\text { todos sus hallazgos, nuevas doctrinas y } \\
\text { observaciones raras hasta el tiempo } \\
\text { presente y muchas advertencias } \\
\text { necessarias para la cirugía: según el } \\
\text { methodo con que se explica en nuestro } \\
\text { teatro de Madrid }\end{array}$ & $\begin{array}{l}\text { Madrid, } \\
\text { España }\end{array}$ & Español & 1764 & $\begin{array}{l}\text { Texto con } \\
\text { imágenes } \\
\text { intercaladas }\end{array}$ & $\begin{array}{l}\text { Contiene estampas con } \\
\text { múltiples imágenes en cada } \\
\text { una y tablas explica tivas de } \\
\text { las mismas }\end{array}$ \\
\hline $\begin{array}{l}\text { Tiedemann, } \\
\text { Friedrich }\end{array}$ & Tabulae arteriarum corporis humani & $\begin{array}{l}\text { Múnich, } \\
\text { Alemania }\end{array}$ & Alemán & 1822 & $\begin{array}{l}\text { Atlas del } \\
\text { sistema arterial }\end{array}$ & $\begin{array}{l}\text { Expone el sistema } \\
\text { cardiovascular relacionado } \\
\text { tonooráficamente }\end{array}$ \\
\hline $\begin{array}{l}\text { Tiedemann, } \\
\text { Friedrich }\end{array}$ & $\begin{array}{l}\text { Erklaerungen seiner abbildungen der } \\
\text { pulsadern des menschlichen körpers }\end{array}$ & $\begin{array}{l}\text { Múnich, } \\
\text { Alemania }\end{array}$ & $\begin{array}{l}\text { Alemán, y } \\
\text { latín }\end{array}$ & 1822 & $\begin{array}{l}\text { Texto de } \\
\text { leyendas }\end{array}$ & $\begin{array}{l}\text { Explicación del atlas de } \\
\text { Tiedemann, } 1822\end{array}$ \\
\hline $\begin{array}{l}\text { Chaussier, } \\
\text { François }\end{array}$ & $\begin{array}{l}\text { Planches an atomiques a l'usage des } \\
\text { jeunes gens qui se destinent a létude de } \\
\text { la chirurgie, de la medecine, de la } \\
\text { peinture et de la sculpture }\end{array}$ & $\begin{array}{l}\text { Paris, } \\
\text { Francia }\end{array}$ & Frances & 1823 & $\begin{array}{l}\text { Atlas de } \\
\text { imágenes en } \\
\text { blanco y negro }\end{array}$ & $\begin{array}{l}\text { Las imágenes corresponden } \\
\text { principalmente a divers as } \\
\text { visiones del sistema } \\
\text { locomotor }\end{array}$ \\
\hline
\end{tabular}

Tabla III. Resumen de las características cuantitativas de los textos que contenían ilustraciones anatómicas y que fueron utilizados por los estudiantes de medicina de Chile, desde 1758 y hasta 1840 (pag: paginas. img: imágenes o ilustraciones anatómicas).

\begin{tabular}{|c|c|c|c|c|c|c|c|c|}
\hline Texto o Atlas & $\begin{array}{l}\text { Introducción } \\
\text { o prefacio }\end{array}$ & $\begin{array}{c}\text { Total } \\
\text { páginas }\end{array}$ & $\begin{array}{l}\text { Total páginas } \\
\text { con imágenes }\end{array}$ & $\begin{array}{l}\text { \% páginas con } \\
\text { imágenes }\end{array}$ & $\begin{array}{l}\text { Descripción } \\
\text { de la imagen }\end{array}$ & $\begin{array}{l}\text { Imágenes } \\
\text { a color }\end{array}$ & Índice & Observación \\
\hline Heister, L. (1755) & Ambos & 336 & 11 & $3.27 \%$ & $\mathrm{Si}$ & No & $\mathrm{Si}$ & $\begin{array}{l}\text { Múltiples imágenes por } \\
\text { página }\end{array}$ \\
\hline $\begin{array}{l}\text { Martínez, M. } \\
\text { (1764) }\end{array}$ & Ambos & 599 & 25 & $4,17 \%$ & $\mathrm{Si}$ & No & $\mathrm{Si}$ & $\begin{array}{l}\text { Múltiples imágenes por } \\
\text { página }\end{array}$ \\
\hline $\begin{array}{l}\text { Tiedemann, F. } \\
\text { (1822), Atlas }\end{array}$ & Ninguno & 77 & 75 & $94.93 \%$ & No & $\mathrm{Si}$ & No & $\begin{array}{l}\text { Imagen original en c olor y } \\
\text { boceto de la misma imagen } \\
\text { en blanco v negro }\end{array}$ \\
\hline $\begin{array}{l}\text { Tiedemann, F. } \\
\text { (1822). Anexo del }\end{array}$ & Prefacio & 392 & 0 & $0 \%$ & $\mathrm{Si}$ & No & $\mathrm{Si}$ & $\begin{array}{l}\text { Anexo con las leyendas de } \\
\text { las imágenes del atlas }\end{array}$ \\
\hline $\begin{array}{l}\text { Chaussier, F. } \\
(1823)\end{array}$ & Introducción & 99 & 21 & $21.21 \%$ & $\mathrm{Si}$ & No & No & $\begin{array}{l}\text { imágenes del sistema } \\
\text { locomotor }\end{array}$ \\
\hline
\end{tabular}


(dibujo de líneas), sin color y con todas las estructuras rotuladas en letras y números arábigos (Fig. 3d). El segundo tomo contiene, una descripción anatómica general de cada una de las imágenes contenidas en el primer tomo y las descripciones específicas de los rótulos de las imágenes de esta misma obra. Estas últimas descripciones están ordenadas en tablas (de la primera a la trigésimo octava) y se relacionan con la imagen correspondiente a través de letras y números arábigos. Estas descripciones están desarrolladas en alemán y latín.

4. Chaussier, J. 1823; Esta obra corresponde a un atlas de imágenes en blanco y negro y esta subdividida en 2 apartados que el autor denomina libros (uno de osteología y otro de miología). La obra completa contiene 21 tablas con imágenes, algunas de estas tablas representan una sola estructura o visión (14 de ellas) y otras contienen más de una imagen ( 7 de ellas). La primera parte de la obra (libro primero, osteología), contiene una primera parte con generalidades de osteología. A continuación de esta primera parte, el libro presenta 8 tablas que a su vez presentan 11 imágenes en total. Las primeras 6 imágenes representan el esqueleto humano de un individuo adulto en visión anterior, posterior y lateral (Fig. 4c). A estas imágenes se suman 5 imágenes de esqueleto de un recién nacido, también en múltiples visiones. Todas las imágenes incluyen las descripciones de las rotulaciones presentes en la imagen correspondientes. La segunda parte de la obra (libro 2, miología), contiene una primera parte con generalidades de miología. A continuación de esta primera parte, el libro presenta ocho tablas que representan la distribución de los músculos de un individuo adulto en distintos planos anatómicos, tanto en visión anterior, posterior y lateral. A estas imágenes se suman 5 tablas con 22 imágenes de cabeza y cuello, mano-muñeca y pie-tobillo, en distintas visiones y planos (Fig. 4d). Todas las imágenes incluyen las descripciones de las rotulaciones presentes en la imagen correspondientes.

\section{CONCLUSIONES}

Es importante destacar que antes de la existencia de ilustraciones físicas, la anatomía humana solo se enseñaba en forma práctica durante la disección, pero una vez desarrolladas las técnicas de impresión, las ilustraciones anatómicas, se incorporaron como complemento importante en el estudio anatómico (Cárdenas, 2017). Además, el análisis de los resultados indica que, junto a la evolución de las técnicas de impresión de libros, evolucionó la calidad de las ilustraciones anatómicas, incorporando mayor nivel de detalles y color.

Durante el periodo analizado en Chile ya existía material bibliográfico anatómico ilustrado de origen europeo. Esto permitió que la enseñanza anatómica de la EM33, contara con estos recursos desde sus primeras experiencias, mejorando el aprendizaje de los estudiantes.

También es importante destacar que las imágenes incluidas en libros de texto y atlas disponibles en Chile fueron concebidas por científicos europeos en base a sus investigaciones y concepciones sociales, históricas y culturales predominantes en la Europa del siglo XVIII y XIX y que representaban el cuerpo humano de individuos diferentes a aquellos que poblaban América del sur. Prueba de ello es que anatomistas como Jean Marc Bourgery (francés 1797 - 1852, médico y anatomista), son claros al declarar que en su obra han procurado "describir al hombre de raza caucásica, de una altura de 5 pies, 33 años de edad y dotado de las proporciones más perfectas" (Le Minor \& Sick, 2008). Como se comprenderá, estos individuos no son representativos de la diversidad que caracterizaba (y caracteriza) a los individuos residentes en Latinoamérica y que son el objeto de estudio de nuestra medicina. Probablemente esta euro-visión del cuerpo humano influyó enormemente, en el desarrollo del conocimiento científico de los médicos formados en Chile durante el periodo, transfi-

Tabla IV. Resumen de los tipos de ilustraciones clasificadas según Gomez, S. (2005), Choulant, L. (1852) y Kemp, M. (1990), de las imágenes contenidas en los textos que contenían ilustraciones anatómicas y que fueron utilizados por los estudiantes de medicina de Chile, desde 1758 y hasta 1840 (Orn: ornamental. Ped: pedagógicas. Des: descriptivas. Exp: explicativas. IGD: información gráfica de datos. RdP: representación de una parte. Tip: tipificadas. Esq: esquematizadas. HHA: estilo heroico en el humanismo anatómico. RdR: retórica de lo real. EnE: estilo "no estilo".

\begin{tabular}{|c|c|c|c|c|c|c|c|c|c|c|c|}
\hline & \multicolumn{5}{|c|}{ Gómez, S. (2005) } & \multicolumn{3}{|c|}{ Choulant, L. (1852) } & \multicolumn{3}{|c|}{ Kemp, M. (1990) } \\
\hline & Orn & Ped & Des & $\operatorname{Exp}$ & $I G D$ & $R d P$ & Tip & $E s q$ & $H H A$ & $R d R$ & $E n E$ \\
\hline Heister, L. (1755) & & & $\mathrm{x}$ & & & & $\mathrm{x}$ & & & & $\mathrm{x}$ \\
\hline Martínez, M. (1764) & $\mathrm{x}$ & & $\mathrm{x}$ & & & $\mathrm{x}$ & $\mathrm{x}$ & $\mathrm{x}$ & $\mathrm{x}$ & $\mathrm{x}$ & \\
\hline Tiedemann, F. (1822) & $\mathrm{x}$ & & $\mathrm{x}$ & & & & $\mathrm{x}$ & $\mathrm{x}$ & & $\mathrm{x}$ & $\mathrm{x}$ \\
\hline Chaussier, M. (1823) & & & $\mathrm{x}$ & & & & $\mathrm{x}$ & & $\mathrm{x}$ & & $\mathrm{x}$ \\
\hline
\end{tabular}


riendo estos modelos de pensamiento a los primeros médicos chilenos.

Estamos de acuerdo con el Dr. Gustavo Jirón Latapiat cuando en 1942 indica, "que es necesario revisar nuestros cuadros anatómicos para completar unos y rectificar otros, o bien para llegar a la conclusión, muy sugestiva, que lo que para aquellos es una variedad, para nosotros es lo normal" (Dinator). Pese a esto, hasta el día de hoy no se cuenta con bibliografía representativa de los individuos chilenos y prácticamente la totalidad de la enseñanza de la anatomía en nuestro país sigue basada en textos de origen extranjero.

Es indudable la importancia de los libros de texto que conforman la bibliografía de un curso universitario, no solo entregan el acervo necesario para adquirir el conocimiento y las competencias específicas de la asignatura, sino que también determinan la orientación y el contexto histórico, político y social del momento. El estudio profundo de las características de la formación de médicos en Chile es fundamental para comprender el nacimiento de la identidad profesional, que ha sido de gran influencia en las ciencias de la salud y en la historia político - social de Chile.

SILVA, J.; ARAYA, C.; CÁRDENAS, J.; MANSILLA, B.; LATÍN, A. \& SALAZAR, M. First anatomical atlas used in the training of physicians in Chile. Int. J. Morphol., 38(5):13021310, 2020.

SUMMARY: In Chile, the first doctors were trained at the Universidad Real de San Felipe and the National Institute, between 1758 and 1833, where docents Domingo Nevín, Manuel Chaparro and Pedro Morán, used and recommended the few existing books. The objective of this work was to analyze these books with anatomical illustrations that were used during this period and in which, the first medical students found a visual guide for the understanding of human anatomy and the practice of dissection. For this study, the works of Lorenz Heister (1755), Martin Martínez (1764), Friedrich Tiedemann (1822) and François Chaussier (1823) were analyzed. A synthesis with relevant biographical data was developed for these authors, and for the books a bibliographic, quantitative and descriptive-qualitative analysis was performed. The images were also analyzed according to the classifications of Gomez (2005), Choulant (1852) and Kemp (1990). Regarding the authors of the texts, they were doctors, surgeons, anatomists and / or medical legists, of German, Spanish or French origin. The texts are written in Spanish, French, German and / or Latin. They present images with different levels of detail, in black and white or in color. All the anatomical bibliography used during the period under study is of European origin, transferring through its pages, a reality centered on 18th and 19th century Europe. This biased view of knowledge has been maintained until the present, where the teaching of human anatomy is still based on texts of foreign origin. A profound study of the training characteristics of doctors in Chile, is essential to understand the beginning of a professional identity, which has been important influence in health sciences and the political - social history of Chile.

KEY WORDS: History of Chile; History of medicine; History of anatomy; Anatomical bibliography; Anatomical atlas.

\section{REFERENCIAS BIBLIOGRÁFICAS}

Barros Arana, D. Historia General de Chile. $2^{\mathrm{a}}$ ed. Santiago de Chile, Editorial Universitaria, 2001.

Cárdenas-Valenzuela, J. L. Teaching of anatomy. Use of media in the classroom. Int. J. Morphol., 37(3):1123-9, 2019.

Cárdenas, V. J. L.; Dinator, E. M.; Madariaga, L. J. Description of the anatomical plates of the Universidad de Chile, a National Monument. Int. J. Morphol., 35(2):711-8, 2017.

Chaussier, M. Planches Anatomiques a Lúsages des Jeunes Gens Qui se Destinenta Létude de la Chirurgie, de la Médecine, de la Peinture et de la Sculpture. Paris, Ed. Chez C. L. F. Panckoucke, 1823.

Cruz-Coke, R. Historia de la Medicina Chilena. Santiago de Chile, Andrés Bello, 1995.

Departamento de Estadística del Servicio de Bienestar Estudiantil de la Universidad de Chile. Breve Guía del Estudiante Universitario. Santiago de Chile, Zig-Zag, 1941.

Dinator, M. Catálogo de láminas anatómicas. Estudio de Visualidad sobre las Ilustraciones Científicas del Cuerpo Humano en la Universidad de Chile (1903-1956). Tesis para Optar al Título Profesional de Diseñador Gráfico. Santiago de Chile, Facultad de Arquitectura y Urbanismo de la Universidad de Chile, 2014.

Ferrer, P. Historia General de la Medicina en Chile. Desde el Descubrimiento y Conquista de Chile en 1535, hasta Nuestros Días. Talca, Imp. Talca, 1904.

Grossi, J. Reseña del Progreso Médico en Chile. Valparaíso, Imp. de La Opinión, 1895.

Heister, L. Compendio Anatómico 1ue Brevissimamente Comprehende, y Explica esta Ciencia. Madrid, Imp. de los Herederos de Don Miguel Francisco Rodriguez, 1755.

Hernández, J. La Universidad de Chile. Santiago de Chile, Ed. Universidad de Chile, 1934.

Laval, E. \& Duarte, I. Enseñanza de la medicina en Chile colonial durante el siglo XVIII. El catedrático Domingo Nevín y su alumno Pedro Manuel Chaparro. Rev Chil. Infectol., 33(5):565-9, 2016.

Laval, E. Evolución y desarrollo de la enseñanza de la anatomía en Chile. An. Hist. Med., 6(2):7-75, 1964.

Laval, E. Vida y obra de Fray Pedro Manuel Chaparro. Médico chileno del siglo XVIII. Santiago de Chile, Ed. Universidad Católica, 1958.

Le Minor, J. M. \& Sick, H. (Eds.). J. M. Bourgery. Atlas de Anatomía Humana. Hong Kong, Taschen, 2008.

Martínez, M. Anatomía Completa del Hombre con Todos sus Hallazgos, Nuevas Doctrinas y Observaciones Rara hasta el Tiempo Presente y Muchas Advertencias Necessarias para la Cirugía según el Método que se Explica en Nuestro Theatro de Madrid. Madrid, Imp. de la Viuda de Manuel Fernández, 1764.

Medina, J. La Medicina y los Médicos de la Real Universidad de San Felipe. Santiago de Chile, Soc. Imp. y Lit. Universo, 1928. 
Mellafe, R.; Rebolledo, A. \& Cárdenas, M. Historia de la Universidad de Chile. Santiago de Chile, Universidad de Chile, 1992.

Orrego Luco, A. Recuerdos de la Escuela. Santiago de Chile, Ed. del Pacifico, 1922.

Serrano, S. Universidad y Nación. Chile en el Siglo XIX. Santiago de Chile, Universitaria, 2016.

Silva, J.; Araya, C.; Cárdenas, J.; Salcedo, A.; Mansilla, B.; Hernández, A.; Rodríguez, P.; Salazar, M.; Caracuel, R. \& Espinoza, M. Anatomical bibliography used in the training of physicians in Chile between 1758 and 1840. Int. J. Morphol., 37(3):938-46, 2019.

Sotomayor, O. Medicina. Rasgos biográficos del doctor don Nataniel Cox; rol del médico en las humanidades. Discurso de don Onofre Sotomayor al incorporarse en la Facultad de Medicina. An. Univ. Chile, 33:18599, 1869.

Tiedemann, F. Erklärungen seiner abbildungen der pulsadern des menschlichen kórpers. Carlsruhae, Ed. Verlag der C. F. Müller'schen Hofbuchhandlung, 1822b.

Tiedemann, F. Tabulae arteriarum corporis humani. Carlsruhae, Ed. ex Officina Christiani Friderici Müller, Typographi, Litographi et Bibliopolae Aul, 1822a.
Dirección para correspondencia:

Prof. Dr. Juan Luis Silva Rubilar

Académico - Investigador

Facultad de Medicina y Ciencia

Universidad San Sebastián

Campus Los Leones de Providencia

Dirección Lota 2465, Edificio F

Santiago

CHILE

Email: juan.silva@uss.cl

Recibido : 11-03-2020

Aceptado: 01-05-2020 